C 201

\title{
ダイナミックステレオPIV による水棲生物周りの渦構造の可視化
}

田中 利昌 ${ }^{\circ}$, 永山 勝也, 田中 和博 (九州工業大学)

速水 洋, 荒巻 森一朗 (九州大学)

\author{
Visualization of Vortex Structure around a Loach using Stereoscopic PIV \\ Toshimasa TANAKA, Katsuya NAGAYAMA, Kazuhiro TANAKA \\ Hiroshi HAYAMI, Shinichiro ARAMAKI
}

\begin{abstract}
The propulsion method of the aquatic life is a result of optimization by evolution. Research of the propulsion method is useful for the design of robot that operates efficiently, for example swimming-robot etc. This study is about a loach that swims bending whole body. Our purpose of research is to clarify its swimming mechanism through flow field analysis. We analyzed the three-dimensional flow field around the loach using stereoscopic PIV, about both horizontal cross section and vertical section. As a result, we captured three-dimensional flow field and vortex structure around the loach.
\end{abstract}

Keywords : Stereoscopic PIV, Loach, Vortex

\section{1. 序論}

Lighthill ${ }^{(1)}$ をはじめとする生物の推進研究は, アクアバ イオメカニクスとして注目されている.このような生物の 推進形態などの研究は, 遊泳ロボットなどを効率良く動作 させる為の設計に役立つものであると考えられる.

魚の泳ぎ方には主に 2 種類あり, 体の後方 $1 / 3$ を振幅さ せるアジ形泳法, 体全体を振幅させて泳ぐうなぎ形泳法か ある.アジ形泳法の魚では, 胸䱛を使って推進するものも あるが, うなぎ形泳法であるドジョウなどは, 胸鰭や腹鰖 が未発達で, その影響は非常に少ないものと考えられる. 我々は, 体の屈曲と尾鯺による影響を調査することを目的 とし,うなぎ形泳法で泳ぐドジョウを対象に研究を進めて いる.

これまでに我々は, 屈曲と尾鮨による渦の可視化につい て (2), また尾鯺での縦方向流れや, 方向転換に伴う非定常 流れについての研究を報告している(3).これらの研究では 2 次元の PIV 法を用いて解析を行ってきたが, ドジョウを 含む, 魚の推進時の流れ場は 3 次元的であることが知られ ている.そこで今回は, ドジョウ推進時の流れ場の 3 次元 性を調査する為, ステレオ PIV を用いて解析・実験を行 った.

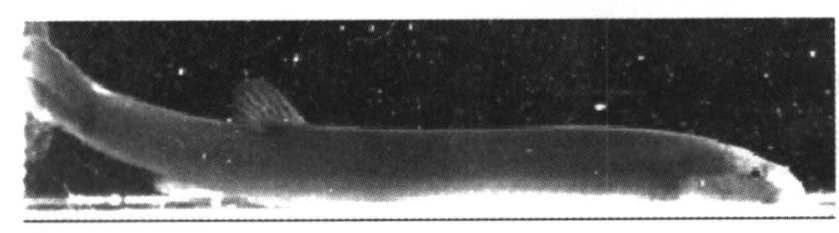

Fig. 1 Black kuhli loach

\section{2. 実煥方法}

今回の実験で用いたドジョウを Fig.1 に示す.このドジ ヨウは, 東南アジア産のブラッククーリーローチ (学名 : Pangio oblonga）という種類であり, 全長は $60[\mathrm{~mm}]$, 体 の幅は頭部付近が最大 $3[\mathrm{~mm}]$, 体の厚みは胸鯺から背鮨 までが最も厚く $8[\mathrm{~mm}]$ である.

Fig.2 に実験装置図を示す.Fig.2(a)ではドジョウ遊泳の 3 次元性を捉えることを目的とし，撮影サイズを $100 \times 100\left[\mathrm{~mm}^{2}\right], 50 \times 50\left[\mathrm{~mm}^{2}\right]$ で, ドジョウ上方からドジ ヨウ全体及び後方の水平断面の可視化・撮影を行った. Fig.2(b)はドジョウ後方垂直断面での流れ場を捉え, Fig.2(a)との対応で渦構造を把握する目的で, 撮影サイ ズ $100 \times 100\left[\mathrm{~mm}^{2}\right]$ とし, ドジョウ後方から撮影を行った. 両実験において, PIV 法を行う為, ドジョウ周囲の流れ 場を粒子眯濁法による可視化を行った. 使用粒子はオルガ

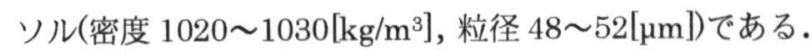
照明は出力 $150[\mathrm{~W}]$, シート厚 $2[\mathrm{~mm}]$ のハロゲンシート 光を用い, 水槽の水位は流れ場に影響が無いように十分な

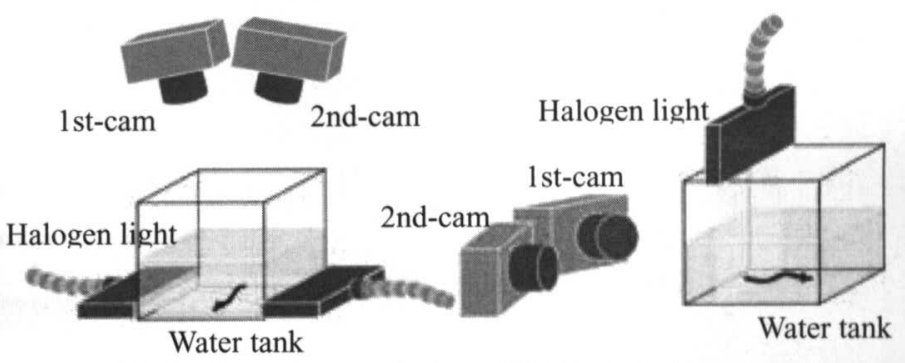

(a): Horizon plane analysis , (b): Vertical plane analysis

Fig. 2. Experimental Equipments 
さを確保し, 実験を行った.画像は, 高速度力メう(Photron, FASTCAM MAX )2 基によって,解像度 $1024 \times 1024$ [pixel], サンプリング周波数 $500[\mathrm{~Hz}]$ として画像を取得した。

実験方法について，Fig.2(a)では水底に平行なシ一ト光 を水底から $2[\mathrm{~mm}], 3[\mathrm{~mm}], 5[\mathrm{~mm}]$ の 3 断面に照明し撮 影を行った.また，Fig.2(b)ではドジョウの垂直断面，ド ジョウがシート光を潜り抜けて泳いでいく際の尾觰側か ら撮影を行った.なお, 水平断面撮影時のシ一ト光の位置 は水底からの高さであるが, ドジョウは主に水底を泳ぐ性 質がある為,これはドジョウ厚み方向の位置と同じと考え られる.ここで，シート光の位置が $2[\mathrm{~mm}], 3[\mathrm{~mm}]$ の場 合はドジョウの厚み中心付近にシート光がある状態, $5[\mathrm{~mm}]$ の場合はドジョウの背鱛がシート光より上にある 状態となる。两実験において，ドジョウが静止流体中を泳 ぐ様子を連続して撮影した(ダイナミック PIV(4)). 解析に ついてはPIV 解析ソフト CACTUS 3.1 を用い, 結果の可 視化には FIELD VIEW 8 を用いた。

\section{3. ステレオPIV 解析結果}

\section{1 水平断面の荤いによる流れ場の变化}

撮影サイズ $100 \times 100\left[\mathrm{~mm}^{2}\right]$ で解析した結果をシート光 位置 $2[\mathrm{~mm}], 3[\mathrm{~mm}], 5[\mathrm{~mm}]$ で図 3.(a), (b)，(c)に示す. (b)，(c)に関してシート光位置，ドジョウ遊泳の性質より 体の形状を確認できていない. また, 各シート光位置にお ける撮影は同時刻ではない為, 定量的な一致は無い。しか し，定性的な評価を行うには十分だと考えられる。ここで， 表示方法は 2 次元のべクトルに加え, 面外速度成分を等高 線で示している.なお，図中に記入されている知印は渦の

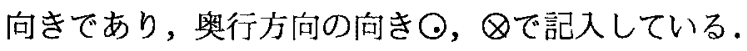

この比較において, シート光を水底から $2[\mathrm{~mm}]$ の位置 に照明した場合, ドジョウの厚みの中心より下にシート光 が当たっている状態にあり, $5[\mathrm{~mm}] に$ 関してはドジョウの 尾鰖はシート光よりも低い位置にある.また, 各実験にお けるドジョウの速度, 尾䱠の速度, 周波数, 尾鰭の振幅を Table.1 にまとめる.

ドジョウ後流に着目すると,渦と渦の間で極端に大きさ の異なるべクトルが見られる.また，そのベクトルは大き な面外速度成分を有し，下降して上昇する流れが確認でき る.これは垂直面方向に旋回する渦があるのではないかと 考えられる. また, 高さ方向による 3 次元性の変化に着 目すると, シート光位置が高くなるにつれて, 後方の渦と 渦の間で面外速度成分の生じている範囲が広がる様子を 捉えることができた。つまり，垂直方向に旋回する渦が存 在し, 発達していっている為に現れたものであると考えら れる。

\section{2 ドジョウ後方の推測される洞㭻造}

ステレオ PIVによる解析結果と, 水底付近で泳ぐドジ ヨウの性質より,ドジョウ後流の瀜構造の発生メカニズム はFig.4のようなものと考えられる。
I はドジョウが尾鱪を振ることで周囲の流体を動かす 様子, II は発生する渦の 3 次元的な形状，IIIは渦の発達す る様子を示している。

ドジョウが泳ぐ際には，全身を大きく振幅させるため， 周囲ではIのような流れ場が形成され考えられる。また， ドジョウは通常, 水底付近を泳いでいる為, 水底の影響も 受ける為，IIのような渦を作る．このとき渦はドジョウの 背中側でも形成される。ここで，尾鯺と流体の接触面樻よ り, 背中と流体の接触面積が大きくなる為, 背中側の渦は 比較的長大なものとなる.これが渦と渦の間に現れた大き なベクトルの原因となると考えられる.そして，このよう な形の渦となるため, シート光の位置が低いほど水平方向 の渦度は明確に現れる.その後，IIIのように背中側で生じ た渦が発達していき, 尾鰙を押し出した方向に流れていく ことでFig.4のような流れ場が現れたと考えられる.

Vectors $(\mathrm{Vx}, \mathrm{Vy})$, Color $\mathrm{Vz}-0.1[\mathrm{~m} / \mathrm{s}]-0.1[\mathrm{~m} / \mathrm{s}]$ $\longrightarrow 0.1[\mathrm{~m} / \mathrm{s}]$

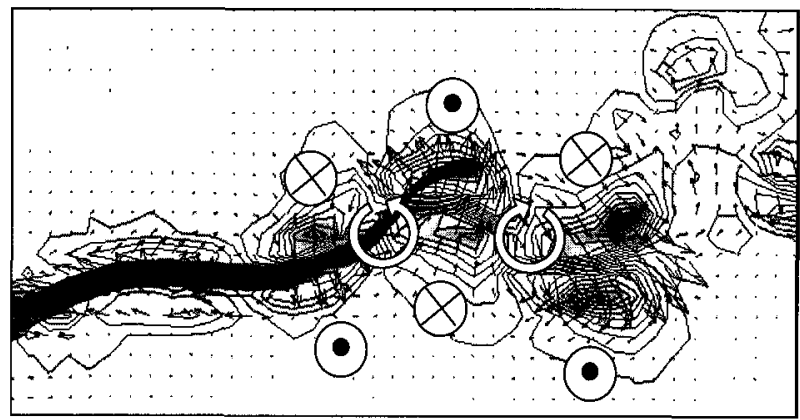

(a) $2[\mathrm{~mm}]$

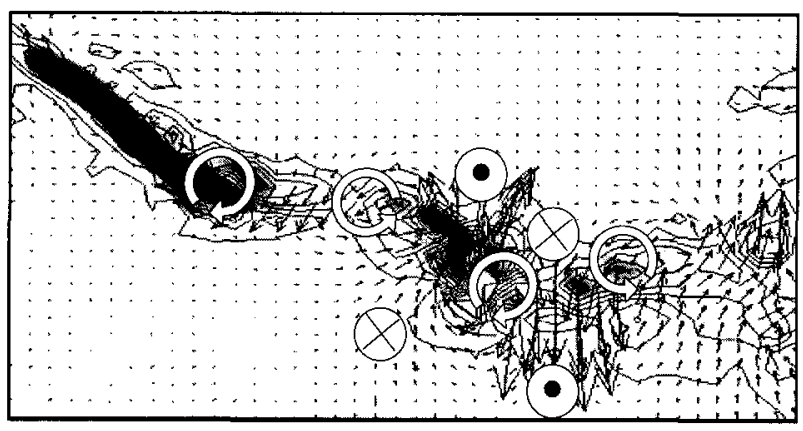

(b) $3[\mathrm{~mm}]$

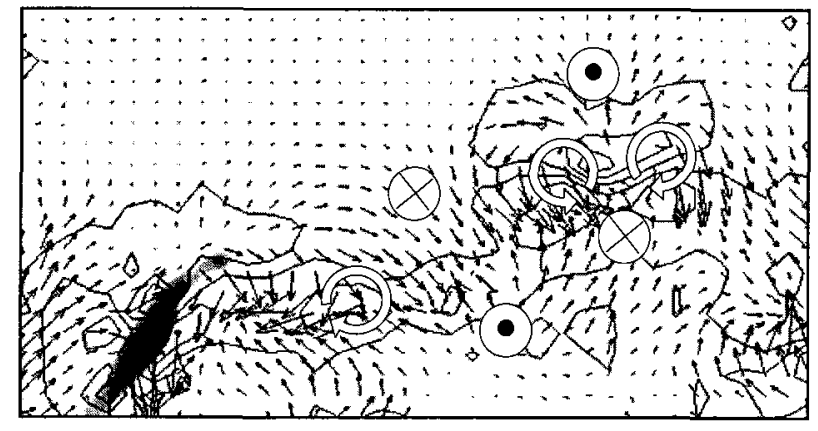

(c) $5[\mathrm{~mm}]$

Fig. 3 Velocity map in horizontal plane $\left(100 \times 100\left[\mathrm{~mm}^{2}\right]\right)$ 


\section{3 垂直断面の解析結果}

撮影サイズ $100 \times 100\left[\mathrm{~mm}^{2}\right]$ で垂直断面の可視化・撮影を 行った実験結果を，水平断面の結果と共に Fig.5(a)，(b)， (c)，(d)に示す.（a)は垂直断面計測時，シート光の上に尾 鰖が残った状態であり，(b)はその後ドジョウの振幅が 1 周期程度経過した時刻の解析結果である。ただし，垂直断 面の結果と水平断面の結果は同時に撮影を行っていない 為, 定量的な一致は無い.さらに, 垂直断面撮影時にはシ 一ト光を過ぎ去った後のドジョウの形状は確認できない 為，定性的な比較のみを行う。それそれの図において， Fig.5(a), (b)は水平断面, Fig.5(c), (d)は直断面であり， それぞれの図中の太線 $\mathrm{H} \cdot \mathrm{H}, \mathrm{V} \cdot \mathrm{V}$ は対応するシート光の位 置である．Fig.5(a)に記入している渦は，Fig.5(c)の面外 速度成分にも対応する箇所があり，加えて垂直方向の渦が 確認できる.これは Fig.4のIにに示した渦が捉えられたも のと考えられる.この㵝が Fig.5(b)ではより明確に現れた。 一方, 水平方向の渦は Fig.5(d)の垂直断面の解析結果から は確認できなくなっている。ここで，図中の記号 $\mathrm{A}$ 垂直 方向の渦である.この渦は同時計測でないために異なる位 置に生じているが, 流れ場の回転の方向を考慮すると，垂 值方向の渦に相当するものであるといえる.

\section{4 摄影サイスの这いによる流れ场の解析結果}

撮影サイズ $50 \times 50\left[\mathrm{~mm}^{2}\right]$ で解析した結果を Fig.6(a)，(b)， (c)に示す。(c)に関してシート光位置, ドジョウ遊泳の性 質から，体の形状をはっきり確認できていない為, 体の形 状は細い．また，同時刻の解析結果ではない為，定量的な 一致は無い。ここで，各シート光位置のドジョウの速度， 尾䱛の速度，周波数，尾鯺の振幅をTable.2.にまとめる.

EXP.1 と 3 を比較すると, どちらも同じような渦発生 構造を形成している.撮影サイズ $100 \times 100\left[\mathrm{~mm}^{2}\right]$ で確認で きた垂直方向に旋回する渦は，撮影サイズ $50 \times 50\left[\mathrm{~mm}^{2}\right]$ より,ドジョウの頭部, エラ付近にかけて発生され，ドジ ヨウの推進力によって次第に後方へ移り，後方で確認でき たものと考えられる.また, 水平断面シート光位置の違い によって，以下の性質を捉えることができた。

・体周り速度成分に関しては，垂直方向よりも水平方 向の成分が大きい。

- 尾鮨以降の速度成分に関しては, 水平方向より垂直 方向の速度成分が大きい.

このことから，管状の渦構造を発生，成長させる際，主に 推進に大きな影響を持つと考えられる水平方向成分が強 く，放出する際は体全体を水底に留めさせる為に，垂直方 向成分が強くなると思われる。

Table. 1 Loach swim data $\left(100 \times 100\left[\mathrm{~mm}^{2}\right]\right)$

\begin{tabular}{|c|c|c|c|c|}
\hline Fig. No. & $\begin{array}{c}\text { Swim Speed } \\
{[\mathrm{m} / \mathrm{s}]}\end{array}$ & $\begin{array}{c}\text { Wave Speed } \\
{[\mathrm{m} / \mathrm{s}]}\end{array}$ & $\begin{array}{c}\text { Frequency } \\
{[\mathrm{Hz}]}\end{array}$ & $\begin{array}{c}\text { Amplitude } \\
{[\mathrm{mm}]}\end{array}$ \\
\hline (a) $2[\mathrm{~mm}]$ & 0.200 & 0.2891 & 6.0 & 8.2 \\
\hline (b) $3[\mathrm{~mm}]$ & 0.084 & 0.2891 & 5.7 & 10.9 \\
\hline (c) $5[\mathrm{~mm}]$ & 0.163 & 0.3256 & 6.6 & 5.4 \\
\hline
\end{tabular}

I

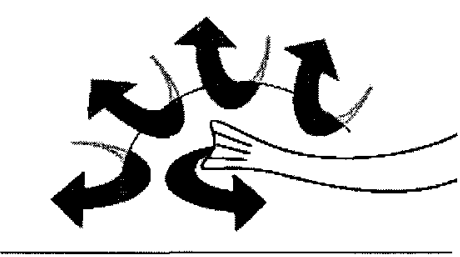

II

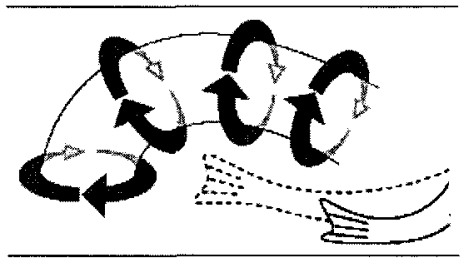

III

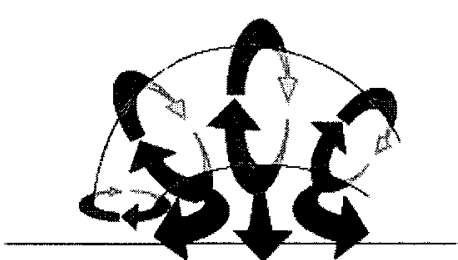

Fig. 4 Proposed mechanism of vortex generation Color $\mathrm{Vz}-0.1[\mathrm{~m} / \mathrm{s}]$ $\longrightarrow 0.1[\mathrm{~m} / \mathrm{s}]$

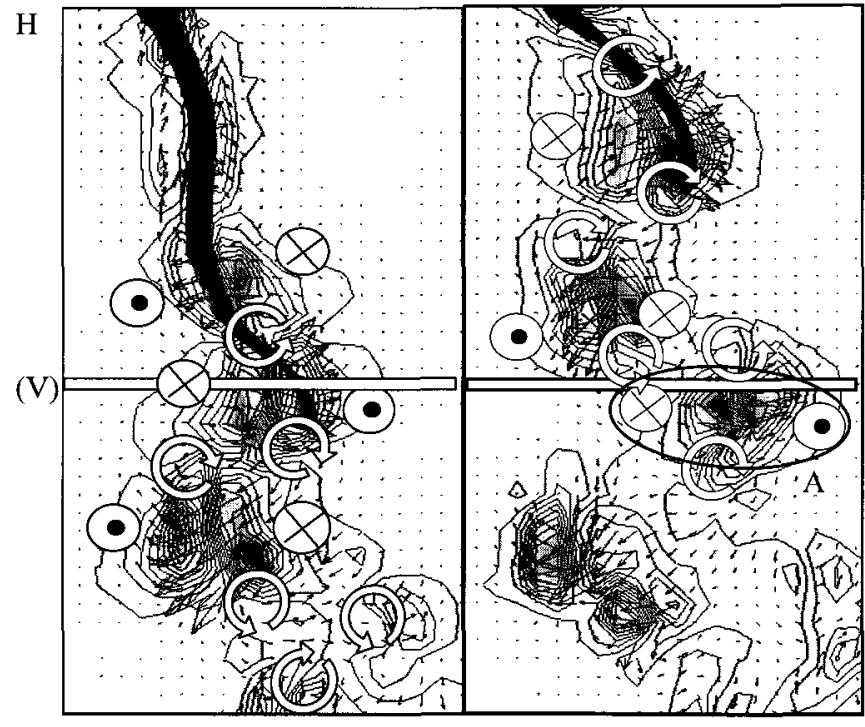

(a) $\mathrm{Vz}$ velocity $(\mathrm{t} / \mathrm{T}=0)$

(b) Vz velocity $(\mathrm{t} / \mathrm{T}=1)$

Vectors $(\mathrm{Vx}, \mathrm{Vz}), \quad$ Color $\mathrm{Vy} \quad-0.1[\mathrm{~m} / \mathrm{s}] \quad 0.1[\mathrm{~m} / \mathrm{s}]$ $\rightarrow 0.1[\mathrm{~m} / \mathrm{s}]$
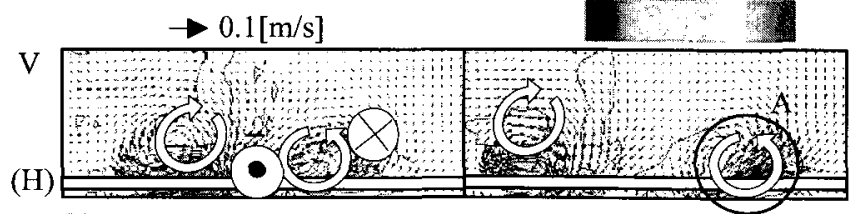

Fig. 5 Result of horizontal cross section and vertical section
(c) Vy velocity $(\mathrm{t} / \mathrm{T}=0)$
(d) Vy velocity $(/ T=1)$

Table. 2 Loach swim data $\left(50 \times 50\left[\mathrm{~mm}^{2}\right]\right)$

\begin{tabular}{|c|c|c|c|c|}
\hline Fig. No & $\begin{array}{c}\text { Swim Speed } \\
{[\mathrm{m} / \mathrm{s}]}\end{array}$ & $\begin{array}{c}\text { Wave Speed } \\
{[\mathrm{m} / \mathrm{s}]}\end{array}$ & $\begin{array}{c}\text { Frequency } \\
{[\mathrm{Hz}]}\end{array}$ & $\begin{array}{c}\text { Amplitude } \\
{[\mathrm{mm}]}\end{array}$ \\
\hline (a) $2[\mathrm{~mm}]$ & 0.331 & 0.424 & 8.33 & 12.74 \\
\hline (b) $3[\mathrm{~mm}]$ & 0.189 & 0.336 & 5.00 & 10.00 \\
\hline (c) $5[\mathrm{~mm}]$ & 0.257 & 0.391 & 7.65 & 11.75 \\
\hline
\end{tabular}




\section{5 ドジョウ周囲に推測される洞槽造}

これまでのステレオの解析結果より,ドジョウ周团の渦 構造メカニズムは Fig.7のようなものと考えられる.

ドジョウは届曲して泳ぐ際，まず頭部付近から尾鱪 $(\mathrm{A} \rightarrow \mathrm{B})$ にかけて，推進力を得る為，水平方向に強い速度 成分を持つ管状の渦構造を形成する. そして, 遊泳するこ とによって, 形成した洞構造は次第に後方へ移動し, 尾鯺 から放出される $(\mathrm{B} \rightarrow \mathrm{C})$. そのとき，渦構造の垂直方向速 度成分は水平方向よりも強くなる.これは，ドジョウの体 全体を水底に押し付ける為の力を得て泳いでいる為では ないかと考えられる。

\section{4. まとめ}

ステレオ PIV を用いてドジョウ周囲の流れ場の様子を 調查した.ははじめにドジョウ周囲の流れ場の水平断面を, シート光位置を変えて 3 断面, 可視化・撮影し, 調査を行 い,ドジョウ後方で垂直方向に旋回する渦を確認すること ができた.さらにこの結果より 3 次元的な渦構造を推測し， 検証のためにドジョウ周囲の流れ場の垂直断面を可視 化・撮影し，調查を行った。この調查の結果では推測した 渦構造は正しいものと考えられる.また, 水平断面の撮影 サイズを $50 \times 50\left[\mathrm{~mm}^{2}\right]$ に拡大し調查した結果, ドジョウ体 周りにも垂直方向に旋回する渦を確認することができた. この渦が発達・移動した結果, 撮影サイズ $100 \times 100\left[\mathrm{~mm}^{2}\right]$, 特にドジョウ後方において確認できたものであると考え られる。

今後は, 今回推測した渦構造が水底ではどのように影響 しているのかを調查する必要がある。

\section{参考文献}

(1) 2. M.J. Lighthill: Annu. Rev. Fluid Mech., vol.44, (1970)

(2) K. Nagayama and K. Tanaka: The $6^{\text {th }}$ KSME-JSME Thermal and Fluids Engineering Conference. FH.03 CD-ROM, 2005

（3）可視化情報, Vol.25 Suppl. No. 1 C204 pp.211-214 (2005)

（4）可視化情報, Vol.25, No.96 (2005), pp.20-24
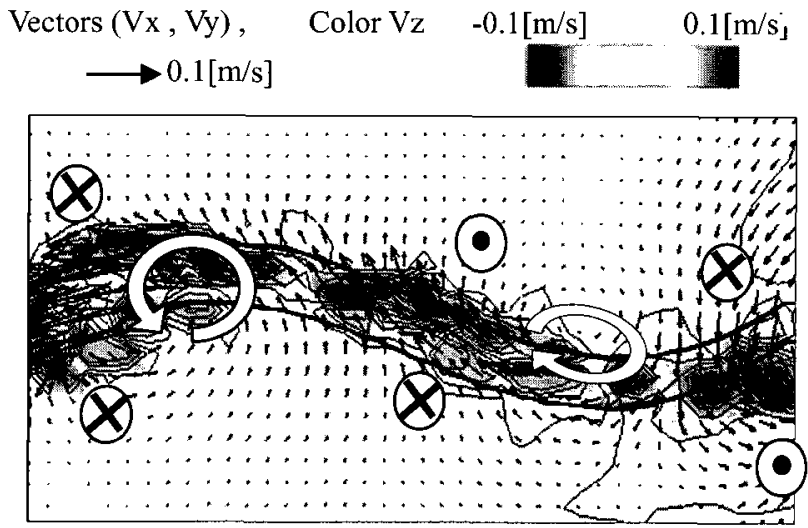

(a) $2[\mathrm{~mm}]$

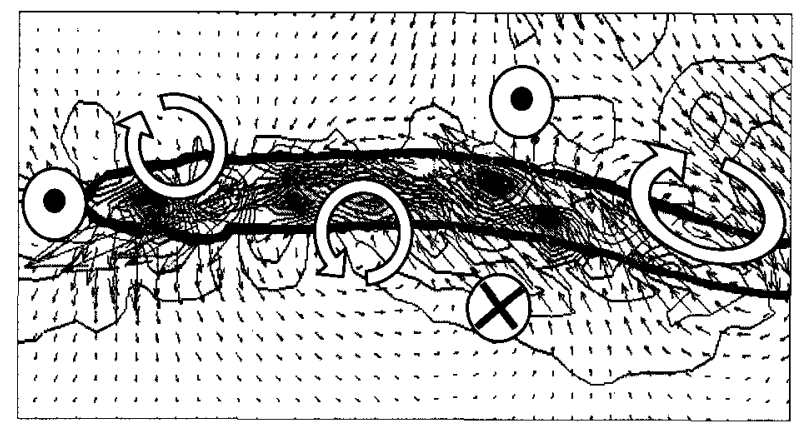

(b) $3[\mathrm{~mm}]$

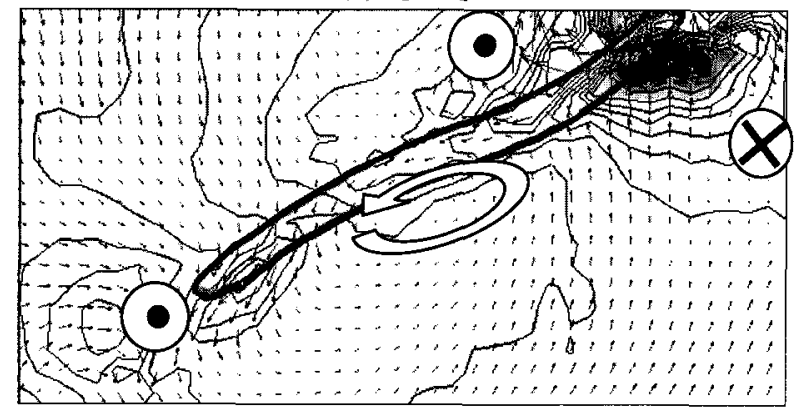

(c) $5[\mathrm{~mm}]$

Fig. 6 Velocity map in horizontal plane $\left(50 \times 50\left[\mathrm{~mm}^{2}\right]\right)$
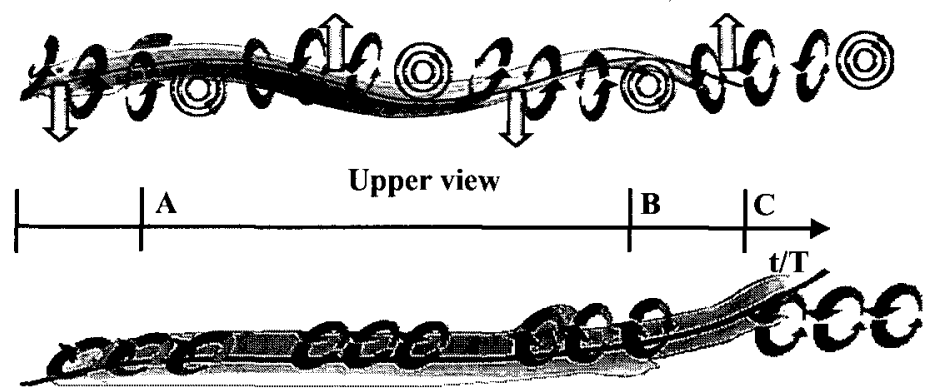

Side view

Fig. 7 Proposed vortex image around the body 